\title{
PENGARUH INOVASI LAYANAN DAN KEUNGGULAN POSISIONAL PADA KINERJA PEMASARAN
}

\author{
Anshar Daud \\ Fakultas Ekonomi dan Bisnis Universitas Diponegoro \\ e-mail: anshar.daud@gmail.com
}

\begin{abstract}
The effect of customer orientation toward marketing performance still have a difference in result of studies. To examine the relationship between the these variables, a conceptual model constructed with mediation by service innovation and positional advantage. A survey was conducted in PT. Telkom Indonesia with 226 respondents to test the model. AMOS Program is being used to test the model, the data andto analyze the relationships between the construct. The result finds that thesubmitted hypothesis are supported. Five of the six hypotheses proved significant, whereas one of the rest is not significant is the relationship between customer orientation and marketing performance. Mediating variables shows a good role with significant results, while the effects indirectly through positional advantage is more powerful than via service innovation.
\end{abstract}

Keywords: Service Innovation, customer orientation, positional advantage, marketing performance. http://dx.doi.org/10.20885/jsb.vol20.iss1.art6

\begin{abstract}
Abstrak
Pengaruh orientasi pelanggan terhadapkinerja pemasaran masih memiliki perbedaan hasil studi. Untuk mengkaji relasi antar keduanya dikonstruksi suatu model konseptual dengan mediasi inovasi layanan dan keunggulan posisional. Sebuah survei dilakukan di PT. Telkom Indonesia dengan 226 respondenuntuk menguji model tersebut. Dengan memanfaatkan program AMOS, model dan data dijalankan untuk menganalisa relasi antar konstruk dan dukungannya terhadap hipotesis yang diajukan.Outputnya menunjukkan bahwa 5 dari 6 hipotesis yang ada terbukti signifikan, sedangkan 1 sisanya tidak signifikan yaitu hubungan antara orientasi pelanggan dan kinerja pemasaran. Variabel mediasi menunjukkan peranyang baik dengan hasil signifikan, sementara efek tidak langsung melalui keunggulan posisional lebih kuat dibanding via inovasi layanan.
\end{abstract}

Kata Kunci: Inovasi Layanan, Orientasi Pelanggan, Keunggulan Posisional dan Kinerja Pemasaran.

\section{PENDAHULUAN}

Terdapat empat elemen yang menjadi faktor penting dalam suatu kegiatan pemasaran yaitu perusahaan (Company), pelanggan (Customer), pesaing (Competitor) dan perubahan (Change) (Kertajaya, Hermawan, Yuswohady, Taufik, Sonni, Anwar, Joewono, dan Mussry, 2002). Interaksi keempat komponen tersebut menentukan intensitas persaingan dan dinamika pasar. Aspek perubahan berfungsi sebagai value migrator yang mempengaruhi ketiga faktor lainnya dan menggeser landskap bisnis dari kondisi yang stabil (certain) menjadi tidak menentu (uncertain) atau dari sesuatu yang semula penting (important) menjadi tidak penting (uncertain) dan sebaliknya. Sementara, pelanggan berperan sebagai value demander yang senantiasa bergerak dalam suatu lingkup industri. Mereka sewaktu-waktu bisa berpindah atau berhenti (lost) dari produsen eksisting dan menjadi pelanggan baru (new) bagi penyedia lainnya atau tetap bertahan (committed) pada perusahaan yang sama (Kertajaya et al, 2002 ).

Hal yang disampaikan di atas tidak jauh berbeda dengan konsep orientasi pasar dalam literatur pemasaran. Konsep tersebut diperkenalkan oleh Slater dan Narver (1990) serta Kohli dan Jaworski (1990). Bagi Kohli and Jaworski (1990), orientasi pasar memiliki 3 unsur yaitu (1) intelligence generation, (2) intelligence dessemination dan (3) responsiveness. Sementara dari Slater and Narver (1990) 
juga menyebut 3 komponen yakni (1) customer orientation, (2) competitor orientation dan (3) interfunctional coordination. Suatu bisnis disebut berorientasi pasar jika budayanya secara sistematis dan menyeluruh berkomitmen terhadap penciptaan nilai superior berkelanjutan kepada pelanggannya. Situasi tersebut bisa terjadi jika perusahaan senantiasa berupaya untuk mengoleksi, mengkonsolidasikan dan memanfaatkan semua informasi terkait pelanggan, pesaing, pemasok, regulator dan faktor lain yang mempengaruhi proses penciptaan nilai pelanggan (Slater and Narver, 1994). Elemen fundamental dari filosofi bisnis adalah konsep pemasaran, penjelmaannya berupa kemampuan perusahaan untuk mengaktualisasikannya dalam setiap aktifitas dan prilaku keorganisasian perusahaan baik internal maupun eksternal. Perusahaan yang konsisten menggunakan konsep pemasaran, disebut sebagai perusahaan yang berorientasi pasar. Sementara konsep pemasaran sendiri terkait dengan koordinasi dan integrasi semua fungsi yang memungkinkan pencapaian maksimum profit jangka panjang perusahaan (Kohli and Jaworski, 1990).

Aspek inti dari orientasi pasar adalah fokus pada pelanggan, tugas semua perusahaan dan pihak-pihak yang terkait di dalamnya untuk selalu berusaha menciptakan dan memberikan nilai superior kepada pelanggan. Seluruh untaian jejaring rantai pasokan (supply chain) perusahaan dan setiap titik kontak dengan pelanggan sepatutnya memberi nilai tambah bagi nilai superior dimaksud (Slater and Narver, 1994).

\section{KAJIAN PUSTAKA}

Pada studi ini, unsur orientasi pelanggan dari Slater dan Narver digunakan sebagai komponen dasar dalam mensintesa model. Peneliti menemukan adanya hasil studi yang berbeda pada hubungan antara orientasi pelanggan dengan kinerja. Satu pihak mengatakan bahwa relasi dari orientasi pelanggan ke kinerja tidak mempunyai pengaruh atau signifikansi. Matanda and Ndubisi (2009) melakukan studi untuk menguji hubungan kedua variabel tersebut dengan menempatkan suplier perceived value creation sebagai mediasinya. Efek tidak langsung menunjukkan hasil yang signifikan, namun terjadi sebaliknya pada hubungan lang- sung antara orientasi pelanggan dengan kinerja pemasaran, bukan saja tidak signifikan tetapi arahnya juga negatif.

Selanjutnya Smirnova, Naudé, Henneberg, Mouzas, dan Kouchtch (2011b) meneliti perusahan industri di Rusia untuk melihat relasi antara orientasi pasar dengan kinerja bisnis. Dari tiga elemennya, hanya orientasi persaingan yang berdampak langsung sedangkan dua sisanya yakni orientasi pelanggan dan koordinasi lintas fungsi dimediasi oleh kapabilitas relasional. Studi lain yang menguatkan bahwa hubungan antara orientasi pelanggan dengan kinerja adalah tidak signifikan ditunjukkan oleh Beitelspacher, Tokman, Adams, dan Glenn Richey (2012) dan Huhtala, Sihvonen, Frosen, Jaakkola, dan Tikkanen (2014). Dengan didukung oleh keempat hasil tersebut, maka pada bagian ini dapat disebut bahwa orientasi pelanggan tidak berpengaruh langsung terhadap kinerja.

Berbeda dengan apa yang telah dibahas di atas, disini beberapa hasil penelitian memperlihatkan hasil yang berkebalikan. Bila sebelumnya hanya hubungan tidak langsung yang memberi dampak maka mereka justru mampu membuktikan bahwa orientasi pelanggan berpengaruh langsung dan signifikan bagi kinerja pemasaran. Mulai dari Ledwith and O'Dwyer (2008), studinya menginvestigasi hubungan antara orientasi pasar, keunggulan produk dan dampak peluncuran produk terhadap kinerja organisasi dengan mediasi kinerja produk baru. Objek studi adalah perusahan kecil menengah (SME) dan perusahaan besar. Mereka menemukan bahwa untuk segmen SME, ada efek langsung dari orientasi pelanggan kepada kinerja organisasi sedangkan segmen perusahaan besar hanya variabel peluncuran produk yang berpengaruh pada kinerja. Selain itu, Smirnova, Henneberg, Ashnai, Naudé, dan Mouzas (2011a) menggunakan dua metode untuk menguji hubungan antara orientasi pelanggan dengan kinerja. Pertama, mereka meneliti bagian pembelian pada 148 perusahaan industri dan hasilnya tidak signifikan. Kedua, mereka menggunakan model dyadic yaitu dua kelompok responden diteliti bersamaan (bagian pembelian dan bagian pemasaran), dengan jumlah sampel yang sama, yakni 148. Hasilnya, metode kedua ini lah yang menunjukkan hasil bahwa orientasi pelanggan berdampak signifikan pada kinerja. Fakta 
empiris yang sama dibuktikan oleh dua artikel lain yang menemukan adanya dampak langsung dari orientasi pelanggan ke kinerja pemasaran, yaitu (Liu, Ke, Wei, dan Hua, 2013) dan (Balas, Gokus, dan Colakoglu, 2014)

Berangkat dari fenomena adanya kesenjangan penelitian (research gap) antara orientasi pelanggan dengan kinerja sebagaimana dipaparkan di atas, baik Kohli dan Jaworski (1990) maupun Slater dan Narver, $(1990 ; 1994)$ sama-sama menyebutkan bahwa orientasi pasar sangat penting bagi perusahaan untuk memberikan nilai terbaik bagi pelanggannya. Dari dua studi yang dilakukan, Slater and Narver (1990) dan Slater and Narver (2000) menemukan bukti yang konsisten bahwa orientasi pasar berdampak pada kinerja, bahkan output riset kedua lebih baik dari pada sebelumnya. Meskipun demikian, riset lain yang lebih baru masih meninggalkan perbedaan hasil. Kemudian, variabel kinerja sendiri dalam banyak literatur menggunakan istilah yang berbeda-beda. Misalnya kinerja organisasi (Ledwith and O'Dwyer, 2008), kinerja bisnis (Matanda and Ndubisi, 2009; Smirnova et al., 2011a; Smirnova et al., 2011b; Balas et al., 2014; Huhtala et al., 2014), kinerja perusahaan (Liu et al., 2013; Ozkaya, Droge, Hult, Calantone, dan Ozkaya, 2015), kinerja keuangan (Jaakkola, Möller, Parvinen, Evanschitzky, dan Mühlbacher, 2010; Cheng and Krumwiede, 2012) dan kinerja pemasaran (Beitelspacher et al., 2012; Cheng and Krumwiede, 2012). Hal yang menarik adalah sebutan kinerja perusahaan dan kinerja bisnis karena pada umumnya, satuan pengukurannya adalah kinerja keuangan dan kinerja pemasaran. Disamping itu, indikator (observed variable) yang diukur ada kalanya sama meskipun terminologi kinerja yang digunakan berbeda.

Ide dasar penentuan model atau kerangka konseptual penelitian ini dielaborasi dari tiga model studi sebelumnya, yakniGrawe,
Chen, dan Daugherty (2009); Beitelspacher et al. (2012) dan Cheng and Krumwiede (2012). Dari ketiga sumber tersebut, muncul variabel orientasi pelanggan, inovasi layanan, dan kinerja pemasaran. Sedangkan variabel lainnya, yaitu keunggulan posisional, diambil dari Hult and Ketchen (2001); Carbonell and Rodriguez (2006). Dengan memiliki 4 variabel, maka dapat disintesis menjadi sebuah model konseptual riset seperti pada gambar 1 .

\section{Customer Orientation (CO) dan Positional Advantage (PA)}

Elemen penting orientasi pelanggan (customer orientation) berkaitan dengan proses memelihara hubungan dan improvisasi terhadap nilai superior bagi pelanggan. Bahkan merekrut calon karyawan terbaik dan memberi training, memotivasi karyawan dan menyediakan penghargaan adalah salah satu bagian dari orintasi pelanggan tersebut. Dalam konteks tertentu, perusahaan dapatmelibatkan pelanggannya guna membangkitkan loyalitas mereka (Slater and Narver, 1994). Orientasi pelanggan merupakan inti kesuksesan suatu bisnis melalui deseminasi dan internalisasi yang baik dalam organisasi perusahaan kepada setiap jajaran. Dengan integrasi yang solid, orientasi pelanggan akan membentuk kompetensi inti perusahaan baik internal maupun ekternal (Brännback, 1999). Manfaat orientasi pelanggan adalah mendekatkan perusahaan dengan pelanggannya dan memberi posisi terbaik untuk belajar dan menerima umpan balik. Dengan demikian, perusahaan dapat secara cepat dan efisien dalam mengantisipasi perubahan kebutuhan dan keinginan pelanggan. Hubungan yang intens dengan pelanggan tertentu membuka kesempatan untuk melakukan kolaborasi atau ko-kreasi dalam pengembangan produk yang baru (Hillebrand, Kemp, dan Nijssen, 2011).

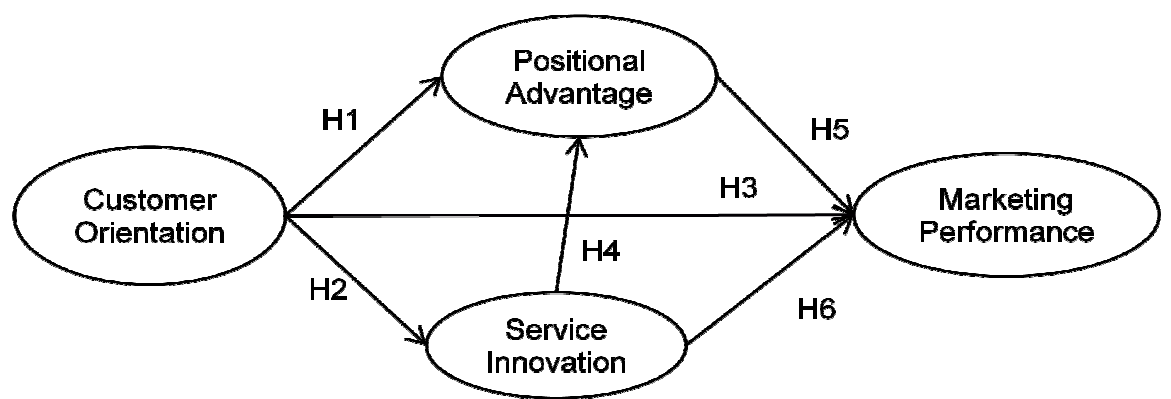

Gambar 1. Model konseptual penelitian 
Slater and Narver (1994) menekankan bahwa orientasi pasar bermuara pada upaya menciptakan nilai superior bagi pelanggan. Agar dapat melakukan hal tersebut, perusahaan membutuhkan keunggulan daya saing yang kuat dan itu hanya dapat terjadi jika disertai kemauan dan kemampuan untuk mengeksplorasi dan mengeksploitasi sumber daya yang dimiliki (Vytlacil, 2010). Keunggulan daya saing (competitive advantage) dapat ditinjau dari dua aspek, yakni keunggulan diferensiasi dan keunggulan biaya. Kedua faktor tersebut merupakan komponen dari keunggulan posisional (Vytlacil, 2010). Kecepatan inovasi erat kaitannya dengan daya saing dan mempengaruhi keunggulan posisional (positional advantage) dan kinerja produk (Carbonell and Rodriguez, 2006).

Studi yang dilakukan oleh Hult and Ketchen (2001); Langerak (2003) dan Vytlacil (2010) menunjukkan adanya hubungan antara orientasi pelanggan dengan keunggulan posisional. Dengan dasar hal ini, dapat dirumuskan hipotesis $\mathrm{H} 1$ sebagai berikut:

H1: Orientasi pelanggan suatu perusahaan mempunyai hubungan dan pengaruh positif terhadap keunggulan posisionalnya.

\section{Customer Orientation (CO) dan Service Innovation (SI)}

Inovasi diperlukan sebagai respon atas berbagai perubahan seperti teknologi, pasar, regulasi, ekonomi, dan sosial politik serta ekspektasi dan kecemasan konsumen. Menurut Bessant et al. (2005), inovasi merepresentasi inti proses pembaharuan dalam setiap organisasi. Selain mengubah penawaran, ia juga mengubah cara menciptakan dan mengantarkan seluruh penawaran tersebut sebagai konsekuensi untuk tetap bertahan dan bertumbuh. Artikel yang membahas tentang inovasi baik dalam sisi akademis maupun praktis tentu sangat banyak. Rowley et al. (2011) melakukan studi untuk mengidentifikasi dan memetakan sejumlah hal terkait inovasi dari berbagai sumber. Mereka kemudian membagi tipe inovasi menjadi 4 kelompok, yaitu (1) inovasi produk, (2) inovasi proses, (3) inovasi posisi dan (4) inovasi paradigma. Bagian pertama meliputi inovasi produk (goods), inovasi layanan, gabungan produk dan layanan serta inovasi teknis. Kemudian bagian kedua menyangkut teknis, produksi, administrasi, struktur organisasi, manusia, manajemen dan organisasional. Lalu bagian ketiga terkait komersialisasi pemasaran dan sistem bisnis.

Studi yang hampir sama datang dari Jon-Arild (2013), pendekatannya melalui kategorisasi, yakni inovasi berbasis institusi dan inovasi berdasarkan faktor ekonomi.Dalam aspek institusi terdapat inovasi kultural, inovasi politis dan inovasi sosial. Sedangkan pada segi ekonomi ada inovasi keorganisasian, inovasi material, inovasi layanan dan inovasi pasar. Inovasi material sendiri memiliki elemen inovasi produk, inovasi teknologi, inovasi proses produksi dan inovasi bahan baku dan bahan sejenisnya. Windahl (2015) sendiri membagi inovasi produk menjadi 4 jenis, meliputi inovasi modular, inovasi arsitektural, inovasiinkremental dan inovasi radikal, terminologi ini berlaku pada sisi pelanggan maupun pemasok.

Inovasi layanan (service innovation) adalah kebaharuan atau perbaikan yang signifikan pada konsep layanan yang diaplikasikan secara praktis. Wujudnya bisa pembaharuan saluran interaksi konsumen, sistem distribusi dan konsep teknologi atau kombinasinya (Wikipedia, 2015). Inovasi layanan dapat berbentuk inovasi inkremental dan inovasi radikal. Inovasi inkremental berkaitan dengan kebutuhan nyata konsumen, sedangkan inovasi radikal menunjukkan adanya perubahan mendasar pada layanan yang baru dan memberi manfaat layanan yang nyata menurut Cheng and Krumwiede (2012).

Penelitian yang membangun hubungan antara orientasi pelanggan dengan inovasi layanan adalah (Grawe et al., 2009; Cheng and Krumwiede, 2012). Dengan menggunakan bukti tersebut, hipotesis $\mathrm{H} 2$ dirumuskan sebagai berikut:

H2: Orientasi pelangn suatu perusahaan memiliki hubungan dan bepenaruh positif terhadap derajat inovasi layanannya.

\section{Customer Orientation dan Marketing Performance}

Studi yang membahas hubungan antara orientasi pelanggan dengan kinerja relatif banyak, beberapa diantaranya adalah (Ledwith and O'Dwyer, 2008; Smirnova et al., 2011a; Liu et al., 2013; Balas et al., 2014). 
Keseluruhan studi tersebut membahas relasi antara orientasi pelanggan dengan kinerja. Karena itu dapat dirumuskan hipotesis H3 sebagai berikut:

H3: Orientasi pelanggan suatu perusahaan memiliki hubungan dan berpengaruh positif terhdap kinerja pemasarannya.

\section{Service Innovation (SI) dan Positional Advantage (PA)}

Sebelumnya telah dibahas bahwa kinerja dalam literatur pemasaran menggunakan beberapa istilah yang berbeda namun outputnya berasosiasi dengan kinerja pemasaran atau kinerja keuangan. Dalam studi ini digunakan terminologi kinerja pemasaran. Studi Beitelspacher et al. (2012) dan Cheng and Krumwiede (2012) keduanya mendukung pengunaan istilah dimaksud. Relevan dengan hal ini, Grawe et al. (2009) menguji hubungan antara MO dengan MP menggunakan mediasi SI. Hasilnya menyebutkan bahwa relasi antara SI dengan MP berpengaruh signifikan. Temuan ini diperkuat oleh Cheng and Krumwiede (2012) yang menyatakan bahwa SI berkontribusi positif yang nyata kepada kinerja pemasaran maupun kinerja keuangan. Dengan demikian, maka dapat diformulasikan hipotesis $\mathrm{H} 4$ berikut:

H4: Inovasi layanan suatu perusahaan memiliki hubungan dan berpengaruh positif terhadap keunggulan posisionalnya.

\section{Positional Advantage dan Marketing Per- formance}

Hult and Ketchen (2001)menempatkan keunggulan posisional sebagai mediator penuh antara orientasi pasar, kewirausahaan, keinovasian dan pembelajaran organisasi untuk memprediksi kinerja. Langerak (2003) dalam risetnya menemukan bahwa keunggulan diferensiasi berdampak pada kinerja, sedangkan keunggulan biaya rendah tidak signifikan pada kinerja. Studi yang sama juga dilakukan oleh Vytlacil (2010) dengan menggunakan orientasi pasar sebagai antecedent-nya. Kedua studi tersebut sama-sama membicarakan tentang relasi antara keungulan posisional dengankinerja. Karena itu dapat dirumuskan hipotesis H5 sebagai berikut:

H5: Keunggulan posisional suatu perusahaan mempunyai hubungan dan penaruh positif dengan kinerja pemasarannya.

\section{Service Innovation dan Marketing Perfor- mance}

Sebelumnya telah dibahas bahwa kinerja dalam literatur pemasaran menggunakan beberapa istilah yang berbeda namun keluarannya berasosiasi dengan kinerja pemasaran atau kinerja keuangan. Dalam studi ini digunakan terminologi kinerja pemasaran. Studi Beitelspacher et al. (2012) dan Cheng and Krumwiede (2012) keduanya mendukung pengunaan istilah dimaksud. Relevan dengan hal ini, Grawe et al. (2009) menguji hubungan antara orientasi pasar dengan kinerja pemasaran menggunakan mediasi inovasi layanan. Hasilnya menyebutkan bahwa relasi antara inovasi layanan dengan kinerja pemasaran berpengaruh signifikan. Temuan ini diperkuat oleh Cheng and Krumwiede (2012) yang menyatakan bahwa inovasi layanan berkontribusi positif yang nyata kepada kinerja pemasaran maupun kinerja keuangan. Dengan demikian, maka dinyatakan hipotesis H6 sebagai berikut:

H6: Inovasi layanan suatu perusahaan mempunyai pengaruh dan hubungan yang positif dengan kinerja pemasarannya.

\section{METODOLOGI PENELITIAN}

\section{Lokasi dan Waktu Penelitian}

Pada akhir tahun 2014 yang lalu PT. Telekomunikasi Indonesia, Tbk (selanjutnya disingkat Telkom) meluncurkan sebuah produk baru dengan merek IndiHome. Layanan tersebut merupakan gabungan (bundling) 3 komponen produk yaitu telepon, internet dan IPTV. Nama generik jasa ini dalam industri ICT (information dan communication technology) adalah IPTV (internet protocol television) triple play. Sebagai sebuah produk baru, tentu IndiHome menjadi objek yang menarik untuk diteliti dan dikaji secara ilmiah khususnya dalam bidang pemasaran.

Survei penelitian ini dilaksanakan dengan 2 cara yakni offline dan online. Untuk offline lokasinya bertempat di kantor Telkom Regional IV Semarang,sedangkan pada survei online, lokasinya tidak ditentukan secara spesifik, responden bisa berada dikantor Telkom mana saja yang tersebardi seluruh Indonesia.Survei dilakukan selama 6 minggu pada bulan Juni-Juli 2015. 


\section{Sampel dan Pengumpulan Data}

Sampel survei dipilih menggunakan metode judgment sampling, yaitu karyawan dengan kategori/posisi supervisor, Asisten Manager, Manager dan General Manager hingga Vice President atau sederajat. Alasannya adalah karena mereka dengan kualifikasi tersebut memiliki product knowledge dan wawasanyang relevan terhadap informasi yang diperlukan. Instrumen kuisioner didesain menggunakan skala ala Likert dengan rentang nilai 1 sampai dengan 10. Angka 1 identik dengan sangat tidak setuju (STS) dan angka 10 menunjukkan sangat setuju (SS), sementara angka 5 mengindikasikan sikap yang netral $(\mathrm{N})$.

Bagi responden offline, kuisioner langsung dibagikan di lokasi kerja masingmasing sehingga bisa langsung diisi dan dikembalikan saat itu juga atau dijemput lagi beberapa hari kemudian. Sedangkan untuk responden online, kuisioner dikirim melalui email menggunakan aplikasi Google Form, sehingga setiap responden selesai mengisi kuisionernya maka hasilnya langsung terupdate secara realtime pada panel aplikasi.

\section{Pengembangan Pengukuran}

Sesuai dengan model konseptual penelitian pada gambar 1, dikembangkan skala pengukuran yang diadopsi dari beberapa sumber dengan mengelaborasi indikator yang sudah ada, kecuali pada konstruk keunggulan posisional, indikator ketiga dan keempat dikembangkan sendiri oleh peneliti. Setiap konstruk direfleksikan oleh 4 indikator, detailnya dapat dilihat pada tabel 1 .

\section{Uji Instrumen Penelitian}

Untuk mengetahui tingkat kesahihan instrumen penelitian terlebih dahulu dilakukan beberapa pengujian seperti uji asumsi klasik, uji realibilitas dan uji validitas. Pada tahap ini digunakan perangkat lunak SPSS 20 dan AMOS 22 untuk mengolah data hasil survei, outputnya dijelaskan secara detail per bagian, pada halaman selanjutnya.

Tabel 1: Konstruk dan skala pengukuran

\section{Konstruk, Skala pengukuran dan referensi}

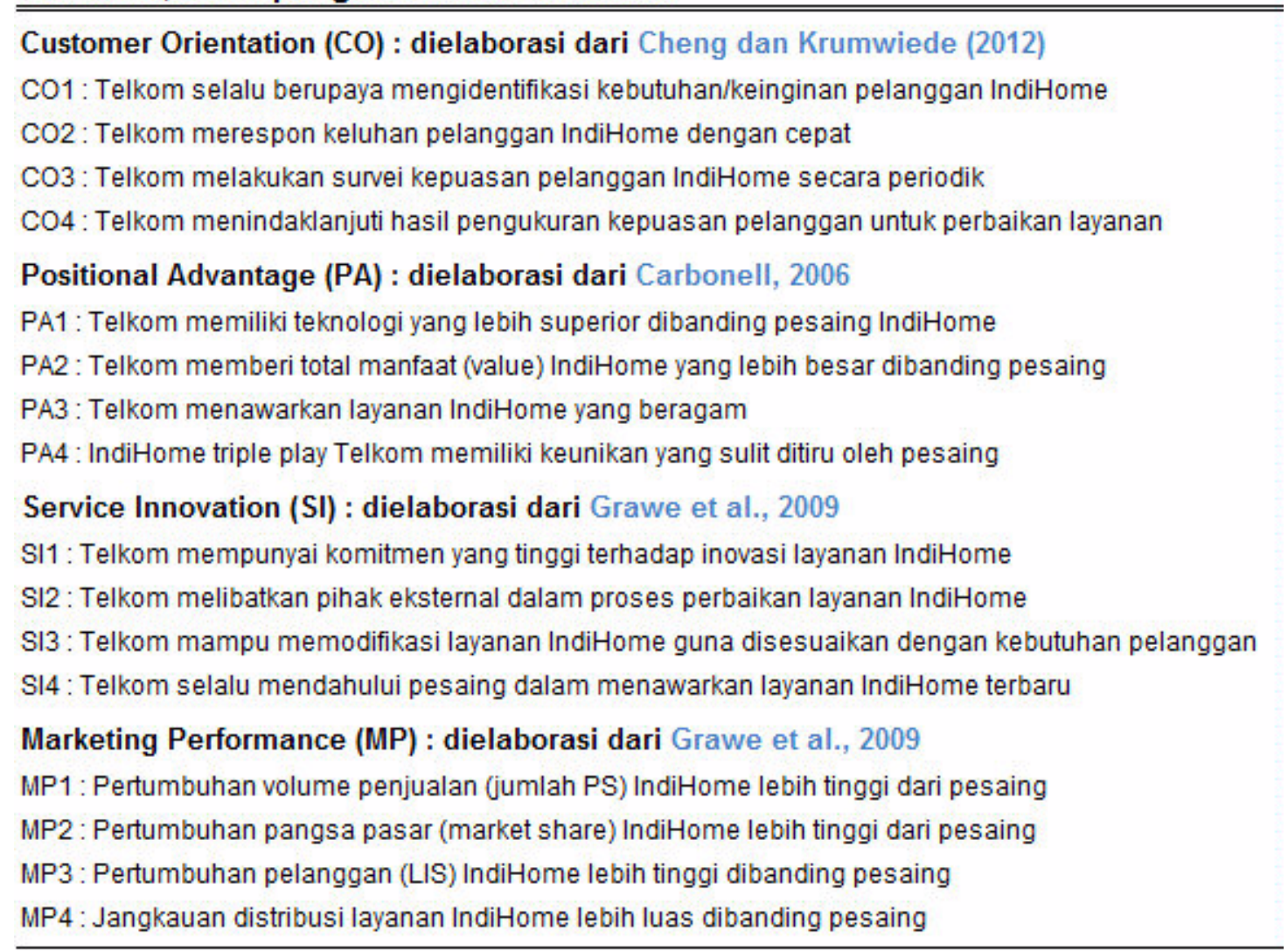




\section{Uji Asumsi Klasik}

Uji klasik meliputi analisis terhadap kasus multikolinieritas, autokorelasi, heteroskedastisitas, normalitas dan linieritas data hasil penelitian. Pengujian asumsi klasik pada studi ini hanya meliputi 2 hal saja yaitu kasus multikolenieritas dan normalitas data. Untuk mendeteksi ada tidaknya multikolenieritas, berikut ditampilkan matrik korelasi semua variabel observed. Menurut Ghozali (2013), dua buah variabel dikategorikan memiliki efek multikolenieritas bila koefesian korelasinya lebih besar dari 0,95. Dari tabel 2 dibawah dapat diketahui nilai korelasi terbesar adalah 0,83 terjadi antara MP2 dan MP3 sehingga dapat disimpulkan bahwa pada data penelitian ini tidak memilikidampak multikolenieritas.
Normalitas data dapat dinilai dari 2 aspek, yaitu kemencengan data (skewness) dan keruncingannya (curtosis) baik univariat maupun multivariat. Asesmen terhadap normalitas data yang dilakukan menggunakan program Amos akan mengeluarkan output yang terkait dengan profil tersebut secara simultan sehingga langsung dapat dinilai data mana yang normal dan sebaliknya. Kreteria penilaian yang digunakan untuk menentukan normalitas data adalah rentang skewness $\pm 2,58$ (Ghozali, 2013). Berdasarkan kreteria tersebut dan output Amos pada tabel 3 dapat dikatakan bahwa secara individual semua data variabel observed memenuhi syarat distribusi normal walaupun secara multivariate belum cukup normal.

Tabel 2.Matriks korelasi observed variabel

\begin{tabular}{|c|c|c|c|c|c|c|c|c|c|c|c|c|c|}
\hline \\
\hline & SI1 & PA4 & S14 & CO1 & MP2 & PA3 & MP3 & SI2 & MP1 & PA2 & $\mathrm{SI3}$ & $\mathrm{CO} 2$ & $\mathrm{CO} 4$ \\
\hline SI1 & 1 & & & & & & & & & & & & \\
\hline PA4 & 0,319 & 1 & & & & & & & & & & & \\
\hline S14 & 0,359 & 0,415 & 1 & & & & & & & & & & \\
\hline $\mathrm{CO1}$ & 0,351 & 0,492 & 0,343 & 1 & & & & & & & & & \\
\hline MP2 & 0,353 & 0,584 & 0,323 & 0,375 & 1 & & & & & & & & \\
\hline PA3 & 0,448 & 0,595 & 0,343 & 0,536 & 0,498 & 1 & & & & & & & \\
\hline MP3 & 0,355 & 0,64 & 0,375 & 0,389 & 0,83 & 0,575 & 1 & & & & & & \\
\hline SI2 & 0,525 & 0,381 & 0,438 & 0,41 & 0,433 & 0,437 & 0,446 & 1 & & & & & \\
\hline MP1 & 0,299 & 0,65 & 0,39 & 0,474 & 0,757 & 0,525 & 0,753 & 0,421 & 1 & & & & \\
\hline PA2 & 0,337 & 0,637 & 0,42 & 0,524 & 0,482 & 0,678 & 0,553 & 0,404 & 0,579 & 1 & & & \\
\hline SI3 & 0,486 & 0,364 & 0,433 & 0,37 & 0,373 & 0,443 & 0,427 & 0,518 & 0,425 & 0,428 & 1 & & \\
\hline $\mathrm{CO} 2$ & 0,28 & 0,547 & 0,367 & 0,578 & 0,464 & 0,466 & 0,502 & 0,407 & 0,527 & 0,54 & 0,38 & 1 & \\
\hline $\mathrm{CO} 4$ & 0,322 & 0,518 & 0,287 & 0,558 & 0,455 & 0,615 & 0,509 & 0,438 & 0,478 & 0,582 & 0,36 & 0,718 & 1 \\
\hline
\end{tabular}

Sumber : Data primer (diolah)

Tabel 3.Profil normalitas data

\begin{tabular}{|l|r|r|r|r|r|r|}
\hline \multicolumn{1}{|c|}{ Variable } & min & max & \multicolumn{1}{c|}{ skew } & \multicolumn{1}{c|}{ c.r. } & \multicolumn{1}{c|}{ kurtosis } & \multicolumn{1}{c|}{ c.r. } \\
\hline SI1 & 5 & 10 & $-0,628$ & $-3,515$ & $-0,39$ & $-1,093$ \\
\hline PA4 & 3 & 10 & $-0,581$ & $-3,25$ & 0,015 & 0,041 \\
\hline S14 & 4 & 10 & $-0,872$ & $-4,879$ & 0,206 & 0,578 \\
\hline CO1 & 3 & 10 & $-0,799$ & $-4,471$ & 0,185 & 0,518 \\
\hline MP2 & 5 & 10 & $-0,203$ & $-1,136$ & $-0,828$ & $-2,318$ \\
\hline PA3 & 3 & 10 & $-0,444$ & $-2,485$ & $-0,431$ & $-1,206$ \\
\hline MP3 & 4 & 10 & $-0,209$ & $-1,171$ & $-0,776$ & $-2,173$ \\
\hline SI2 & 4 & 10 & $-0,858$ & $-4,801$ & 0,531 & 1,486 \\
\hline MP1 & 4 & 10 & $-0,251$ & $-1,405$ & $-0,562$ & $-1,572$ \\
\hline PA2 & 3 & 10 & $-0,198$ & $-1,106$ & $-0,537$ & $-1,504$ \\
\hline S13 & 5 & 10 & $-0,54$ & $-3,025$ & $-0,186$ & $-0,521$ \\
\hline CO2 & 2 & 10 & $-0,294$ & $-1,644$ & $-0,306$ & $-0,857$ \\
\hline CO4 & 3 & 10 & $-0,31$ & $-1,738$ & $-0,499$ & $-1,398$ \\
\hline Multivariate & & & & & 50,6 & $\mathbf{1 7 , 5 6 6}$ \\
\hline Sub
\end{tabular}

Sumber : Data primer (diolah) 


\section{Uji Validitas}

Untuk menilai validitas instrumen pengukuran dilakukan analisis CFA (confimatory factor analysis) dengan batas nilai faktor loading adalah minimal 0,7. Meskipun begitu, faktor loading dengan nilai 0,6 hingga 0,5 masih dapat diterima dalam konteks tertentu (Ghozali, 2013).

Mengacu pada gambar 1, maka terdapat 4 konstruk dengan masing-masingnya terdiri atas 4 indikator. Konstruk CO (customer orientation) direpresentasikan oleh $\mathrm{CO} 1$, $\mathrm{O} 2, \mathrm{CO} 3$ dan $\mathrm{CO} 4$ dengan skorCFAberturutturut adalah: 0,$63 ; 0,78 ; 0,76$ dan 0,93 . Sedangkan SI (service innovation) diwakili oleh SI1 = 0,68; SI2 = 0,75; SI3 = 0,71 dan SI4 $=0,58$. Kemudian PA (positional advantage) direfleksikan oleh PA1 $=0,64 ;$ PA2 $=0,86$; PA3 $=0,78$ dan PA4 $=0,75$. Terakhir adalah MP (marketing performance) dengan manifes MP1 $=0,83 ;$ MP2 = 0,90; $\mathrm{MP} 3=0,92$ dan MP4 $=0,49$. Dari sejumlah 16 indikator yang ada, 1 indikator tidak memenuhi syarat nilai $\alpha$ yaitu MP4 sebesar 0,49 dan terpaksa dibuang (di drop) untuk menjaga tingkat validitas instrumen.

\section{Uji Realibilitas}

Selanjutnya penilaian instrumen dilakukan dengan uji kehandalan (realibilitas) menggunakan parameter CR (construct realibility) dan AVE (average variance extract). Indikator lainnya adalah menghitung koefisien Alpha $(\alpha)$ konstruk menggunakan metode Cronbach, namun hasil estimasinya lebih rendah bila dibandingkan dengan CR. Rumus yang digunakan untuk menghitung CR dan AVE mengacu pada Ghozali (2013)halaman 138 dan 140 yaitu:

$$
\begin{gathered}
C R=\frac{\left(\sum_{i=1}^{n} \lambda_{i}\right)^{2}}{\left(\sum_{i=1}^{n} \lambda_{i}\right)^{2}+\left(\sum_{i=1}^{n} \delta_{i}\right)} \quad \lambda=\text { standardized factor loading, } \delta=\text { error variance } \\
\text { Dan }
\end{gathered}
$$

$$
\operatorname{AVE}=\Sigma\left[\lambda_{\mathrm{i}}^{2}\right] /\left[\Sigma \lambda_{\mathrm{i}}^{2}+\Sigma \operatorname{Var}\left(\varepsilon_{\mathrm{i}}\right)\right]
$$

Dengan memanfaatkan kedua formula di atas, maka diperoleh besaran CR, AVE dan akar (sqrt) dari AVE sebagaimana ditunjukkan oleh tabel 4. Secara umum, angka CR dan koefisien $\alpha \geq 0,7$ serta AVE $\geq 0,5$ yang mengindikasikan kondite yang baik kecuali AVE dari SI yang relatif marjinal yaitu 0,466 .

\section{HASIL ANALISIS}

\section{Demografi}

Jumlah kuisioner yang diedarkan pada studi ini adalah 300 paket baik melalui offline maupun online dan dikembalikan dalam keadaan semua item pertanyaan/pernyataan terisi secara lengkap sebanyak 226 responden atau tingkat respon sebesar $75,3 \%$. Setelah dievaluasi dan mengeleminasi data yang tidak valid dan outlier, tersisa 188 data yang layak diolah dengan SPSS dan AMOS untuk menguji model konseptual yang diajukan.

Adapun profil demografi responden yang terlibat dalam survei menurut jenis kelamin adalah responden pria $87,8 \%$ dan wanita $12,2 \%$. Strata pendidikan SMA 15,2\%; Diploma 8,1\%; Sarjana 50,3\% dan Paska Sarjana 26,4\%. Sementara menurut formasi jabatan terdiri dari Supervisor $31,1 \%$; Asisten Manager 26\%, Manager 30,6\%; General Manager $5,1 \%$ dan Vice President atau sederajat $1 \%$.

Tabel 4: Parameter realibilitas instrumen

\begin{tabular}{|l|c|c|c|c|}
\hline \multicolumn{1}{|c|}{ Konstruk } & $\begin{array}{c}\text { Cronbach } \\
\text { Alpha }(\boldsymbol{\alpha})\end{array}$ & $\begin{array}{c}\text { Construct } \\
\text { Realibility }\end{array}$ & AVE & SQRT AVE \\
\hline Customer Orientation (CO) & 0,856 & 0,889 & 0,612 & 0,782 \\
\hline Service Innovation (SI) & 0,767 & 0,776 & 0,466 & 0,683 \\
\hline Positional Advantage (PA) & 0,843 & 0,866 & 0,593 & 0,770 \\
\hline Marketing Performance (MP) & 0,914 & 0,915 & 0,782 & 0,884 \\
\hline
\end{tabular}

Sumber : Data primer (diolah) 


\section{Evaluasi Data dan Model Struktural}

Dengan berbekal 188 data yang valid dilakukan pengujian ulang terhadap validitas dan realibitas sistem dengan menjalankan persamaan model struktural (SEM) secara penuh. Hasilnya diperlihatkan oleh tabel 5. Dari output tersebut, tampak bahwa ada beberapa indikator yang mengalami sedikit penurunan, hal itu terjadi karena adanya pengurangan 2 indikator (CO3 dan PA1). Kedua manifes terkait di drop untuk mendapatkan nilai goodness of fit model yang memenuhi kreteria standar yaitu: Probabilitas (p) $\geq 0,05$; GFI $\geq 0,90$; AGFI $\geq 0,90$; TLI $\geq$ 0,$95 ; \mathrm{CMIN} / \mathrm{DF} \leq 2$ dan RMSEA $\leq 0,08$.

Meskipun kinerja model sedikit menurun namun tetap melampaui nilai baku yang ditentukan baik untuk Cronbach $\alpha, \mathrm{CR}$ maupun AVE, terkecuali AVE dari SI yang cenderung marjinal.

\section{Analisis Persamaan Model Struktural}

Dengan bantuan program AMOS melalui estimasi ML (maximum likelihood), model konseptual dijalankan menggunakan 188 data hasil survei. Model penuh SEM tanpa respesifikasi dengan mengurangi jumlah indikator tertentu dan modifikasi indices (MI) memperlihatkan ukuran goodness yang tidak fit, output nilai Prob 0,000; chi-square 229,552; GFI 0,867; AGFI 0,816; TLI 0,909 dan RMSEA 0,085.

Tabel 5: Parameter validitas dan realibilitas SEM

\begin{tabular}{|c|c|c|c|c|}
\hline Konstruk & $\begin{array}{l}\text { Loading } \\
\text { Faktor }\end{array}$ & $\begin{array}{l}\text { Cronbach } \\
\text { Alpha }(\alpha)\end{array}$ & $\begin{array}{l}\text { Construct } \\
\text { Realibility }\end{array}$ & AVE \\
\hline Customer Orientation & & 0,830 & 0,848 & 0,644 \\
\hline $\mathrm{CO} 1$ & 0,751 & & & \\
\hline $\mathrm{CO} 2$ & 0,770 & & & \\
\hline $\mathrm{CO} 3$ & \multicolumn{4}{|c|}{ di drop } \\
\hline $\mathrm{CO} 4$ & 0,881 & & & \\
\hline Service Orientation & & 0,767 & 0,783 & 0,436 \\
\hline Sl1 & 0,586 & & & \\
\hline SI2 & 0,725 & & & \\
\hline $\mathrm{SI3}$ & 0,702 & & & \\
\hline S14 & 0,619 & & & \\
\hline Positional Advantage & & 0,840 & 0,850 & 0,739 \\
\hline PA1 & \multicolumn{4}{|c|}{ di drop } \\
\hline PA2 & 0,872 & & & \\
\hline PA3 & 0,820 & & & \\
\hline PA4 & 0,847 & & & \\
\hline Marketing Performance & & 0,914 & 0,932 & 0,821 \\
\hline MP1 & 0,916 & & & \\
\hline MP2 & 0,826 & & & \\
\hline MP3 & 0,970 & & & \\
\hline MP4 & & di c & op & \\
\hline
\end{tabular}

Sumber: Data primer (diolah)

Tabel 6. Standar Goodness of Fit Index

\begin{tabular}{llcc}
\hline \multicolumn{1}{c}{ Goodness of fit index } & \multicolumn{1}{c}{ Cut-off Value } & Output & Status \\
\hline Chi-square (CMIN) & Diharapkan kecil & 68,315 & Fit \\
Significance Probability & $\geq 0,05$ & 0,053 & Fit \\
RMSEA & $\leq 0,08$ & 0,043 & Fit \\
GFI & $\geq 0,90$ & 0,945 & Fit \\
AGFI & $\geq 0,90$ & 0,902 & Fit \\
CMIN/DF & $\leq 2,00$ & 1,340 & Fit \\
TLI & $\geq 0,95$ & 0,981 & Fit \\
PGFI & 0 s/d 1 & 0,530 & Fit \\
\hline
\end{tabular}

Sumber : Ferdinand (2014) 

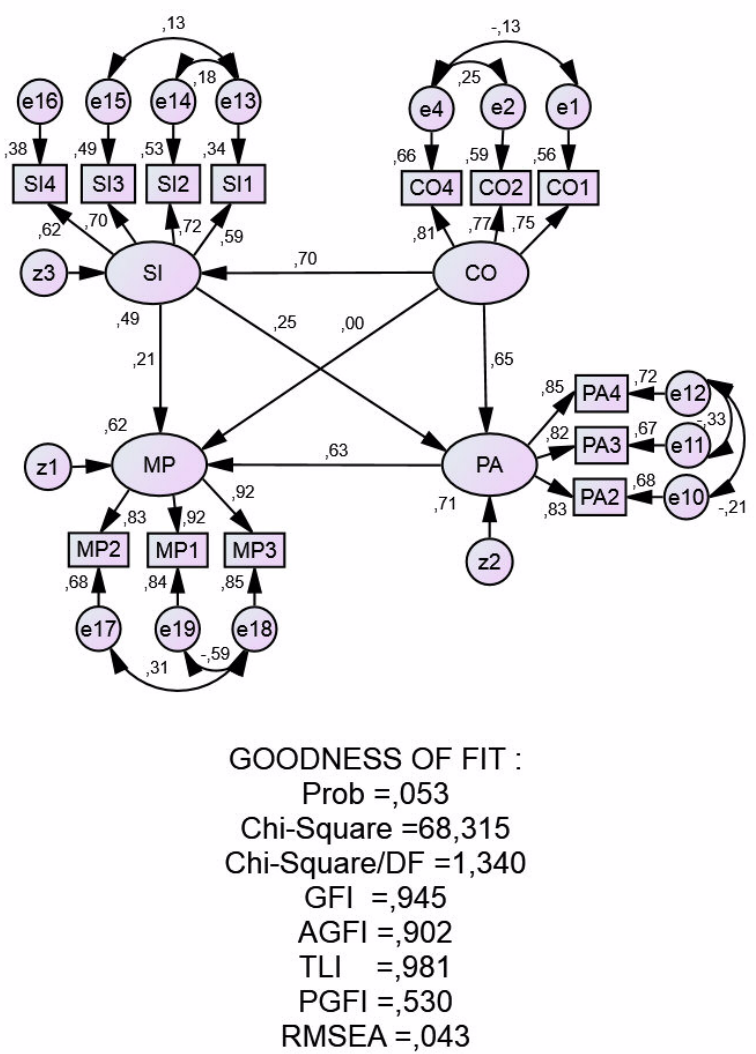

Gambar 2: Diagram SEM respesifikasi

Gambar 2 di atas merupakan format full model hasil respesifikasi yang optimum dengan angka probabilitas $\mathrm{P}=0,053$. Skor $\mathrm{P}$ ini memenuhi syarat fit model yakni $\geq 0,05$ sehingga tentu jauh berbeda dari $\mathrm{P}$ sebelumnya yang hanya 0,000 . Dengan $P=0,053$ diperoleh chi-square 68,315; chi-square/DF 1,34; GFI 0,945; AGFI 0,902; TLI 0,981 dan RMSEA 0,043.

Karena diagram SEM pada gambar 2 sudah fit dan memenuhi semua kreteria goodness of fit, maka dapat dilanjutkan untuk menganalisa relasi antar konstruk model dan mengkonfirmasi hipotesis yang diajukan. Hipotesis H1, H2 dan H6 terbukti signifikan pada level $\mathrm{p}<0,001(0,1 \%)$, sedangkan hipotesis $\mathrm{H} 4$ dan $\mathrm{H} 5$ signifikan pada taraf $\mathrm{p} \leq$ $0,05(5 \%)$, sementara hipotesis H3 tidak signifikan karena nilai p-nya cukup besar $(0,981)$ sehingga sangat jauh dari nilai $\mathrm{p}$ yang disyaratkan yaitu $\leq 0,05$. Dengan demikian 5 dari 6 hipotesis yang diajukan pada studi ini terbukti memiliki hubungan yang positif dan signifikan, sementara 1 hipotesis lainnya (H3) tidak memperoleh dukungan bukti yang memadai. Rangkuman terhadap status hipotesis dan angka statistik pendukungnya ditampilkan oleh tabel 7 sebagai berikut:

Tabel 7.Parameter SEM dan konfirmasi hipotesis

\begin{tabular}{|l|r|r|r|c|}
\hline \multicolumn{1}{|c|}{ Hipotesis } & Koefesien jalur $(\boldsymbol{\beta})$ & Critical Ratio $(\mathbf{t})$ & Prob $(\mathbf{p})$ & Status \\
\hline $\mathrm{H} 1: \mathrm{CO}--->\mathrm{PA}$ & 0,651 & 4,604 & $0,000^{\star *}$ & mendukung \\
\hline $\mathrm{H} 2: \mathrm{CO}-->\mathrm{SI}$ & 0,702 & 5,974 & $0,000^{\star *}$ & mendukung \\
\hline $\mathrm{H} 3: \mathrm{CO}--->\mathrm{MP}$ & $-0,004$ & $-0,023$ & 0,981 & tidak mendukung \\
\hline $\mathrm{H} 4: \mathrm{SI}--->\mathrm{PA}$ & 0,251 & 2,094 & $0,036^{*}$ & mendukung \\
\hline $\mathrm{H} 5: \mathrm{SI}--->\mathrm{MP}$ & 0,212 & 1,958 & $0,050^{\star}$ & mendukung \\
\hline $\mathrm{H} 6: \mathrm{PA}-->\mathrm{MP}$ & 0,628 & 2,216 & $0,000^{\star \star}$ & mendukung \\
\hline
\end{tabular}

Catatan : $\mathrm{CO}=$ cus tomer orientation, $\mathrm{SI}=$ service innovation, $\mathrm{PA}=$ positonal advantage, $\mathrm{MP}=$ marketing performance

* menunjukkan signifikan pada $\mathrm{p}<0.05$ dan ** signifikan pada $\mathrm{p}<0,001$

Sumber : Data primer (diolah) 


\section{DISKUSI DAN KESIMPULAN}

\section{Keterbatasan Penelitian}

Responden studi ini adalah karyawan Telkom dengan latar belakang pendidikan, unit kerja dan lokasi kantor yang berbeda-beda. Meskipun berada dalam satu perusahaan dan mengelola lini produk yang sama namun pengetahuan dan pemahaman mereka tentang produk IndiHome (IPTV triple play) belum tentu seragam. Kondisi tersebut sedikit banyaknya mempengaruhi akurasi dan variasi jawaban mereka terhadap setiap item pertanyaan/pernyataan kuisioner penelitian. Selanjutnya adalah waktu pelaksanaan survei yang relatif singkat menyebabkan sejumlah responden yang berkompeten tidak seluruhnya sempat mengisi kuisioner survei sebagaimana mestinya.

Pada konteks yang lain, dukungan teori terhadap konstruk tertentu misalnya PA (positional advantage) belum begitu memadai sehingga relasi yang terbangun dari variabel lainnya menuju ke PA atau sebaliknya masih memerlukan kajian yang lebih intensif. Selain itu, konstruk SI (service innovation) menghasilkan validitas dan realibitas yang relatif rendah, kondisi tersebut mempengaruhi output model secara keseluruhan. Beberapa simulasi yang dilakukan terhadap full model menunjukkan bahwa setiap perubahan yang terjadi pada salah satu elemen persamaan struktural akan mengubah nilai probabilitas dan parameter model lainnya.

Limitasi berikutnya yang ditemukan dalam penelitian ini adalah adanya 3 indikator yang yang terpaksa dibuang (dropped) yaitu CO3, PA1 dan MP4, padahal secara teoritis ketiganya sudah lazim digunakan dalam sejumlah studi sebelumnya. Eksistensi ketiga indikator tersebut pada model yang diajukan sesuai gambar 1 menyebabkan persamaan struktural tidak mencapaikondisi fit yang disyaratkan.

\section{Rekomendasi Penelitian Lanjutan}

Untuk mengatasi keterbatasan riset yang diungkapkan di atas, maka penelitian selanjutnya patut diupayakan adanya kegiatan pra penelitian untuk menciptakan persepsi dan pemahaman yang relatif sama antara peneliti dan calon responden terhadap objek, tujuan dan metode penelitian. Mekanismenya bisa melalui sosialisasi dalam suatu forum pertemuan, group interaktif di sosial media, video conferenceatau email.

Kegagalan model dan data yang digunakan untuk mencapai kondisi fit tanpa melakukan respesifikasi model dan mengurangi jumlah indikator merupakan peluang bagi peneliti berikutnya untuk menguji dan menganalisis model tersebut dengan melakukan penyempurnaan tertentu baik pada aspek justifikasi teori, konstruksi model maupun akurasi datanya.

\section{Implikasi Akademis dan Manajerial}

Pada bagian awal artikel ini telah disampaikan bahwa relasi antara orientasi pelanggan (customer orientation) dengan kinerja pemasaran (marketing performance) masih meninggalkan riset gap. Kelompok pertama menyebutkan bahwa hubungan keduanya adalah positif signifikan sedangkan pihak lain menyatakan sebaliknya. Sebagaimana terlihat dalam tabel 7, dimana hipotesis $\mathrm{H} 3$ yang menyatakan bahwa "orientasi pelanggan suatu perusahaan memiliki hubungan dan berpengaruh positif terhadap kinerja pemasarannya", ternyata tidak mendapat dukungan dari model dan data hasil riset. Dengan demikian, maka output penelitian ini menguatkan temuankelompok kedua yang mengatakan bahwa orientasi pelanggan tidak berpengaruh terhadap kinerja pemasaran.

Mengacu uraian di atas, maka implikasi akademis artikel ini adalah menambah dan menguatkan temuan riset-riset sebelumnya baik terkait $\mathrm{H} 3$ maupun $\mathrm{H} 1, \mathrm{H} 2, \mathrm{H} 4, \mathrm{H} 5$ dan H6.Sementara untuk implikasi manajerialnya dapat ditinjau dari model strukturalnya. Dari model struktural dapat diketahui bahwa kinerja pemasaran dipengaruhi oleh faktor inovasi layanan dan keunggulan posisional sehingga secara sederhana dapat dikatakan bahwa jika perusahaan ingin memperbaiki kinerja pemasarannya maka perusahaan tersebut seyogyanya mengelola dengan optimal inovasi layanan dan keunggulan posisionalnya. Meskipun orientasi pelanggan tidak berdampak langsung pada kinerja pemasaran namun ia memberi pengaruh melalui inovasi layanan dan keunggulan posisional. 


\section{Kesimpulan}

Studi ini berangkat dari sebuah riset gap antara orientasi pelanggandengan kinerja pemasaran. Untuk menguji riset gap tersebut dibangun sebuah model konseptual yang menghubungkan keduanya dengan 2 variabel mediasi yaitu inovasi layanan dan keunggulan posisional. Untuk menguji model dimaksud, dilakukan survei di Telkom dengan objek produk adalah IndiHome. Dari total 226 kuisioner yang diisi dan dikembalikan oleh responden, kemudian diverifikasi sehingga didapatkan 188 data yang valid.

Dengan menggunakan program AMOS, model dan data tersebut dijalankan sehingga diperoleh hasil seperti pada gambar 2.Semua parameter goodness of fit model memenuhi kreteria sehingga relasi dan hipotesis dapat dinilai lebih lanjut.Hasil estimasi AMOS menunjukkan bahwa 5 dari 6 hipotesis terbukti signifikan pada probabilitas 0,001 untuk H1, H2 dan H6 sedangkan H4 dan H5 signifikan pada probabilitas 0,05 . Sisanya 1 hipotesis yaitu $\mathrm{H} 3$ tidak signifikan.

Mengingat hubungan langsung antara CO dengan MP tidak signifikan, maka pengaruh $\mathrm{CO}$ pada MP didapatkan melalui mediasi SI atau PA. Efek tidak langsung $\mathrm{CO}$ ke MP melalui SI adalah $\beta_{\text {CO-SI }}$ dikali $\beta_{\text {SI-MP }}$ atau $0,702 \times 0,212=0,149$. Sedangkan mediasi oleh PA memberikan efek tidak langsung antara $\mathrm{CO}$ dengan MP sebesar 0,409 ( $\beta_{\text {CO-PA }}$ dikali $\beta_{\mathrm{PA}-\mathrm{MP}}$ atau 0,651 x 0,628). Dengan begitu dapat dikatakan bahwa dalam kaitan mediasi antara CO dengan MP, tampaknya efek mediasi PA lebih dominan dibanding efek mediasi SI dengan ratio sebesar 2,745 kali.

\section{DAFTAR PUSTAKA}

Balas, A. N., O. Gokus, dan S. N. Colakoglu. 2014. exploring the role of external envirnment on determining strategies focus, market orientation, and firm performance of service firms.Academy of Marketing Studies Journal. 18(1).

Beitelspacher, L. S., M. Tokman, F. G. Adams, dan J. R. Glenn Richey. 2012. Retail service-based operant resources and market performance. The International Journal of Logistics Management, 23(3). 408 - 434.
Bessant, J., R. Lamming, H. Noke, dan W. Phillips. 2005. Managing innovation beyond the steady state. Technovation. 25(12). 1366-1376.

Brännback, M. 1999. The concept of customer orientation and its implication for competence development. Innomarket Technical Reports. 1(1).

Carbonell, P., dan A. I. Rodriguez. 2006. The impact of market characteristics and innovation speed on perceptions of positional advantage and new product performance. International Journal of Research in Marketing. 23(1). 1-12.

Cheng, C. C., dan D. Krumwiede. 2012. The role of service innovation in the market orientation-new service performance linkage. Technovation. 32(7-8). 487497.

Ferdinand, A. T. 2014. Structural Equation Model Dalam Penelitian Manajemen, Aplikasi Model-Model Rumit Dalam Penelitian Untuk Skripsi, Tesis dan Disertasi Doktor.In Seri Pustaka Kunci, edited by F. E. d. B. U. Diponegoro. Semarang, Indonesia: BP Undip Undip Press.

Ghozali, I. 2013. Model Persamaan Struktural, Konsep dan Aplikasi Dengan Program AMOS 21. 5 ed. Semarang, Indonesia. Badan Penerbit Undip.

Grawe, S. J., H. Chen, dan P. J. Daugherty. 2009. The relationship between strategic orientation, service innovation, and performance. International Journal of Physical Distribution \&Logistics Management.39(4).282 - 300.

Hillebrand, B., R. G. M. Kemp, dan E. J. Nijssen. 2011. Customer orientation and future market focus in NSD. Journal of Service Management. 22(1): $67-84$.

Huhtala, J.-P., A. Sihvonen, J. Frosen, M. Jaakkola, dan H. Tikkanen. 2014. Market orientation, innovation capability and business performance: Insights from the global financial crisis. Baltic Journal of Management. 9(2). 134 152. 
Hult, G. T. M., dan D. J. Ketchen. 2001. Does market orientation matter- A test of the relationship between positional advantage and performance. Strategic Management Journal.22. 899-906.

Jaakkola, M., K. Möller, P. Parvinen, H. Evanschitzky, dan H. Mühlbacher. 2010. Strategic marketing and business performance: A study in three European engineering countries'. Industrial Marketing Management. 39(8). 1300-1310.

Jon-Arild, J. 2013. Innovation, a systemic perspective - developing a systemic innovation theory. Kybernetes $.42(8) .1195$ - 1217.

Kertajaya, H., M. Hermawan, Yuswohady, Taufik, Sonni, H. Anwar, H. H. Joewono, dan J. Mussry. 2002. Markplus on Strategy. Jakarta: PT Gramedia Pustaka Utama.

Kohli, A. K., dan B. J. Jaworski. 1990. Market orientation: The construct, research propossition, and managerial implications. Jurnal of Marketing. 54. 1-18.

Langerak, F. 2003. The effect of market orientation on positional advantage and organizational performance. Journal of Strategic Marketing, 11(1), 93-115.

Ledwith, A., dan M. O'Dwyer. 2008. Product launch, product advantage and market orientation in SMEs. Journal of Small Business and Enterprise Development. 15(1). 96-110.

Liu, H., W. Ke, K. K. Wei, dan Z. Hua. 2013. Effects of supply chain integration and market orientation on firm performance: Evidence from China. International Journal of Operations \& Production Management. 33(3). 322 346.

Matanda, M. J., dan N. O. Ndubisi. 2009. Market orientation, supplier perceived value and business performance of SMEs. Journal of Enterprise Information Management. 22(4). 384 - 407.

Ozkaya, H. E., C. Droge, G. T. M. Hult, R. Calantone, dan E. Ozkaya. 2015.
Market orientation, knowledge competence, and innovation. International Journal of Research in Marketing. 32(3). 309-318.

Rowley, J., A. Baregheh, dan S. Sambrook. 2011. Towards an innovation-type mapping tool. Management Decision, 49(1), 73 - 86.

Slater, S. F., dan J. C. Narver. 1990. The effect of a market orientation on business profitability. Journal of Marketing. 54(4). 20-35.

1994. Market Oreintation, Customer Value and Superior Performance. Business Horison.

2000. The positive effect of a market orientation on business profitability: A balanced replication. Journal of Business Research. 48. 69-73.

Smirnova, M., P. Naudé, S. C. Henneberg, S. Mouzas, dan S. P. Kouchtch. 2011b. The impact of market orientation on the development of relational capabilities and performance outcomes: The case of Russian industrial firms. Industrial Marketing Management. 40(1). 44-53.

Smirnova, M., S. C. Henneberg, B. Ashnai, P. Naudé, dan S. Mouzas. 2011a. Understanding the role of marketingpurchasing collaboration in industrial markets: The case of Russia. Industrial Marketing Management. 40(1). 54-64.

Vytlacil, L. L. 2010. Market orientation and business performance: The role of positional advantage. Sbool of Business and Technology. Capella University.

Wikipedia. 2015. Service Innovation. http://en.wikipedia.org/wiki/Service_in novation. Diakses tanggal 25 Mei 2015.

Windahl, C. 2015. Understanding solutions as technology-driven business innovations. Journal of Business \& Industrial Marketing. 30(3/4). 378 393. 